\title{
I am a refugee dentist
}

After fleeing Kosovo as a dental student in the 1990s, Vicky's journey to becoming

a registered dentist in the UK was a difficult one that took many years.

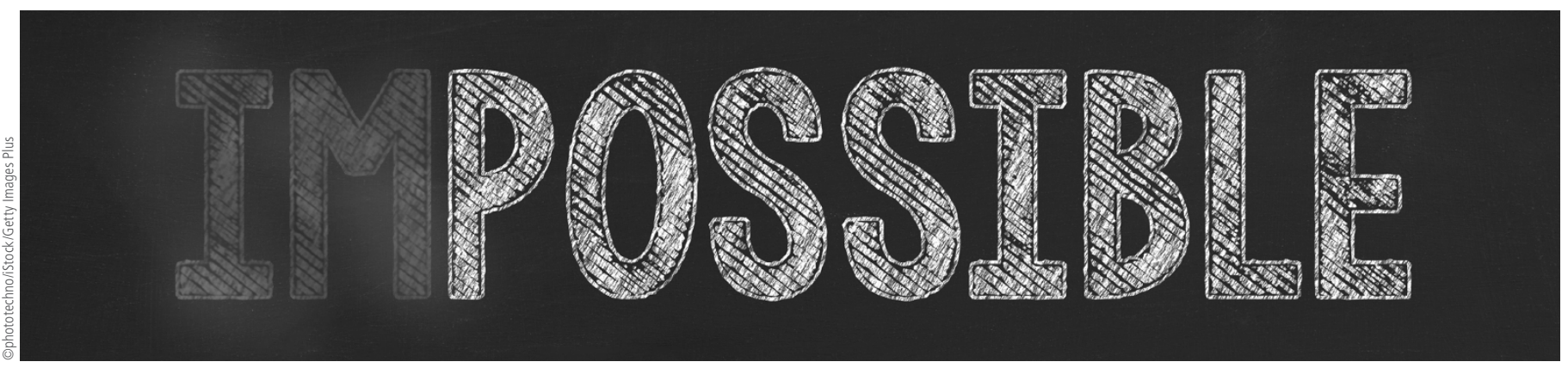

$\mathrm{M}$ y name is Vicky. I am from Kosovo. I came to the UK because of the political circumstances in my country in the 1990 s. After four years of studying dentistry my university closed because of political suppression. Those students who could, went abroad to study for degrees. I could not; I was from a low income family and my father had been suspended from work and I could not work, because we are Albanians and were prevented from this. I am the eldest of four children and I desperately needed a future and to support the family. I came to the UK initially to study English and to work temporarily until life normalised in Kosovo. My boyfriend, also a dental student, joined me. But the situation in Kosovo worsened, I could not return, the university was closed, there was no possibility of work.

Things became even worse back home and I applied for asylum, but always with the hope to return and resume my degree and career. It took eight years to gain refugee status because of the Home Office backlog. All that time I did not know what the future was, I was in limbo. I was not a qualified dentist and it was very difficult to find work here without a reference. I struggled understanding all the different accents and we were on our own. But in the 90s I did get some benefits (asylum seekers now do not receive any benefits). Eventually I got refugee status and applied to all the dental schools in the UK but without success. I started a family and my priority became the children, but I never lost hope, even though by 2000 I should have been long qualified as a dentist and instead I was a refugee away from my family and home.

I enrolled in a dental technician course, graduating after two years and worked for a while. I quickly realised this was not really what I wanted to do. In 2003 I took the difficult decision to try to complete the missing two years of my dental degree in Kosovo. By then my children had settled here so I travelled backwards and forwards between the UK and Kosovo. It was a great strain. In 2005 I graduated in dentistry from Kosovo. I managed
This part of my journey profoundly affected my life and my family, a real rollercoaster. Failing ORE exams was tremendously disappointing and the pressure of the costs made me even more anxious. I paid for it myself from my earnings but it became impossible as it was so expensive and we could not afford this as a family. So I applied to organisations: RAGU (London Metropolitan University) and the Refugee Council who support refugee health professionals, and they covered the ORE costs. I could not have gone through these exams without their support. I was a qualified dentist, very well prepared for all exam sections but

\section{'My husband and many other refugee dentists will never work as dentists. It is very sad that there is so much lost potential from skilled refugee professionals.'}

to find work as a dental nurse, which was very beneficial, and I learnt about NHS and dental practice standards.

I then started the process to gain GDC registration. I discovered that the GDC did not recognise my university as a dental training institution and it took another two years of travelling to and from from Kosovo to get the documents that finally enabled the GDC to recognise the institution as valid. Then I started the GDC's ORE exams. the pressure to pass was so great, I am sure this is why I failed. After four attempts at ORE I felt devastated. But I did not give up and with support I tried again, this time through the LDS route, and I passed at the first attempt.

Throughout the ORE exams I was working part-time as a dental nurse and I had an honorary unpaid contract at King's College for five years as a clinical teacher for dental undergraduates, teaching, and helping with assessments, treatments and final BDS 
14 exams, so I really knew the clinical standards required. At King's I was part of the dental professional team and hoping to become a permanent registered dentist. Now a GDCregistered dentist, I teach two days a week there in a paid post and feel very privileged.

My attempts to secure a place to obtain vocational training equivalence (VTE) were the next obstacle. I had no idea it would be as difficult as it turned out to be. It was especially challenging in London, as it was very competitive. I wanted to work with NHS patients who cannot afford treatment, not only with private patients. This is my responsibility to the $\mathrm{UK}$, to give something back for being able to settle in safely.

I sent many CVs without receiving any replies from dental practices. I eventually found a VTE, but it took one and a half years to find this placement. A colleague at King's who works with me as a clinical teacher helped me find this, and without this help I would not have found it. This cannot be right.

VTE arrangements vary greatly: it is meant to be a supportive mentoring situation, and some are. But in some you work without any payment at all, in some you get minimum pay after you have completed a certain number of UDAs. What can you do but accept what is on offer, though it is financially very hard.

I am a skilled, safe, caring dentist to my patients and the dental team I am with. I hope my skills will be put to good use in the supportive family. Professional integration has been harder; at times I felt very down, like a second-class person, hesitating to go forward. But I could see that I was skilled and I always looked for ways to develop professionally. I am proud of what I have achieved so far and so are my children, friends, RAGU and the Refugee Council.

\section{'I wanted to work with NHS patients who cannot afford treatment, not only with private patients. This is my responsibility to the UK, to give something back for being able to settle in safely.'}

UK very soon after this long journey. My husband and many other refugee dentists will never work as dentists. It is very sad that there is so much lost potential from skilled refugee professionals.

I have been here for many years and by now am well integrated. It was not easy but we have made many friends, through our children - and we are a friendly, approachable and
I hope that people could try to understand a little of what refugee dentists experience and to try to help. Refugee dentists are not here by choice, they are forced here by circumstances. They are accepted by the Home Office, are here to stay, and some are now UK citizens contributing. Yet it is so incredibly hard for refugee dentists to pay for ORE exams and, once through, to find a VTE place. 